\title{
ESA's eye on the oceans
}

\section{London}

THIS month, the European Space Agency (ESA) should launch ERS-1, the first stage of ESA's Earth observation programme, and the most ambitious package of remotesensing microwave instruments yet put into orbit. The satellite will provide a wealth of oceanographic data, which will help to improve climate prediction models, but controversy still surrounds ESA's policy on setting prices for those data. Except for some 200 scientists chosen by ESA as "principal investigators" for the mission, academic researchers will be charged for ERS-1 data at the same prices as those fixed for commercial users.

ERS-1, which will fly in a polar orbit, was due for launch on 3 May, from Kourou, French Guyana. But on Monday this week, problems with the third stage of the Ariane-4 launch rocket had set the launch date back, possibly by more than a week.

The key component of the ERS- 1 payload is the Active Microwave Instrument (AMI). Because clouds are transparent to microwaves, this will give an uninterrupted view of the Earth below. In its Synthetic Aperture Radar (SAR) mode, the AMI will produce detailed radar images of a $100-\mathrm{km}$-wide strip of the Earth's surface. These images will be used in land-use surveys, to monitor oil slicks at sea, and may allow oceanographers to detect ocean fronts, where bodies of cold and warmer water meet.

SAR equipment is not new in space. In 1978, the US National Aeronautics and Space Administration (NASA) Seasat satellite included such a radar device. But Seasat gave only a tantalizing hint of the full possibility of SAR data: the satellite suffered a massive power failure after only 100 days in orbit. The launch of ERS-1 is part of a new surge of interest in SAR imaging. The Soviet Union launched a satellite fitted with SAR earlier this year, and the SAR-equipped Japanese Earth Resources Satellite is due for launch in early 1992.

Unlike the Soviet satellite, ERS-1 will do more than produce SAR images. For most of the time, the AMI will operate in its 'wave' mode, taking snapshot images of a $5-\mathrm{km}$ square every 200 to $300 \mathrm{~km}$ along the ocean surface, or in the 'wind' mode, measuring the backscatter from radar beams angled at 45 degrees to the sea surface. This backscatter can be used to calculate wind speed and direction at the sea surface. These data will be a key input to the World Ocean Circulation Experiment, the largest international collaboration in oceanography.

ERS-1 will also carry a radar altimeter, to measure variation in sea level and the height of ice sheets, and the Along Track Scanning Radiometer, which will measure the water content of the atmosphere and sea surface temperature.

ERS-1 has such an impressive range of hardware in part because ESA spending is decided by industry ministers from ESA member states, which are willing to pay into ESA's space programmes because their space technology industries benefit from the manufacturing contracts that result. But this commercial mindset also influences ESA's data policy, so that academics will be charged the same for ERS-1 data (several

\section{Materials top critical technologies list}

Washington

ANSWERING a congressional plea for the US government to take the lead in setting technology priorities, the White House last week released a list of 22 'critical' technologies.

Separated into six general categories materials, manufacturing, information and communications, biotechnology and life sciences, aeronautics and surface transportation, and energy and environment - the list is heavy on those technologies related to economic prosperity and national security and light on basic research and exploration technologies.

Topping the list are five materials technologies, reaffirming the high priority the Administration places on that field. Earlier this year, White House Office of Science and Technology Policy (OSTP) officials previewed a large, multi-agency materials research initiative that the science office is planning for the 1993 budget (see Nature 350, 365; 4 April 1991).
Computers dominate the rest of the list, with seven key technologies in the category of information and communications. The White House panel's selections were: software; microelectronics and optoelectronics; high-performance computing and networking (also the subject of a new OSTP funding initiative); highdefinition imaging and displays; sensors and signal processing; data storage and peripherals; and computer simulation and modelling.

Biomedical research was represented in only two technologies: applied molecular biology and medical technology.

OSTP is establishing a critical technologies institute to ensure that government research spending reflects the priorities of the list. Following a Bush Administration mandate, government support will be limited to 'generic, precompetitive' technologies, to avoid being put in the position of picking industry winners and losers.

Christopher Anderson hundred pounds for each SAR image) as any other user.

This rigid commercial policy has been pushed most strongly by the British. But some relaxation, perhaps by allowing academics working on environmental research cheaper access to data, is expected for ESA's future remote-sensing satellites. NASA, which has a stronger interest in research than ESA, already takes this line (see Nature 346, 600; 1990). The difficulty of selling environmental remote-sensing data is likely to be a major factor in ESA's future data policy.

Many ESA officials say it is not possible to recover costs by selling remote-sensing data - a view which is supported by the disappointingly low number of applications for data received by the commercial US Landsat satellite.

Peter Aldhous

\section{ASTRONOMY}

\section{Keck telescope twin gets the go-ahead}

\section{Washington}

KECK I, which at 10 metres was to be the world's largest telescope when completed next year, has a competitor for the title. The W. M. Keck Foundation announced last week that it has committed $\$ 74.6$ million to build an identical 10-metre telescope, Keck II.

Like Keck I, the new telescope will be built on the 13,600-foot Hawaiian volcano Mauna Kea by a consortium of Caltech and the University of California. To allow optical and infrared interferometry, the new telescope will be built adjacent to Keck I. Separated by a distance of 85 metres, the two telescopes will have the effective resolution of a telescope with an 85-metre mirror - an unparalleled combination of light-collecting power and spatial resolution for a ground based telescope. Keck I will be completed next year; Keck II is scheduled for completion in 1996. They will be joined on Mauna Kea later in the decade by a Japanese 8-metre infrared telescope that was approved earlier this year.

Christopher Anderson

\section{Correction:}

\section{Gamma-Ray Observatory}

LAST month's account of the launching of the Gamma-Ray Observatory (GRO) (Nature 350, 451; 1991) contained a concise and ac curate description of a grazing incidence photon detector. Unfortunately, such devices work only for X-rays, and GRO has no such thing on board. The two large instruments, EGRET and COMPTEL, are based on scintillators. In EGRET, energetic gamma-rays create electron-positron pairs, whose energy and tracks are used to reconstruct the direction of origin of the incident gamma-ray. In COMPTEL, photons from successive Compton scatterings of a gamma-ray achieve the same purpose. 